\title{
Mobilidade e a atração de viagens de ônibus da área central de Belo Horizonte
}

\author{
Mobility and the bus travel attraction of Belo Horizonte central area
}

Daniela Antunes Lessa[a] (1), Carlos Lobo[b] (1)

[a] Universidade Federal de Ouro Preto (UFOP), Departamento de Engenharia Civil (DECIV), Ouro Preto, MG, Brasil

[b] Universidade Federal de Minas Gerais (UFMG), Instituto de Geociências (IGC), Departamento de Geografia, Belo Horizonte, MG, Brasil

Como citar: Lessa, D. A., \& Lobo, C. (2020). Mobilidade e a atração de viagens de ônibus da área central de Belo Horizonte. urbe. Revista Brasileira de Gestão Urbana, 12, e20190229. https://doi.org/10.1590/2175-3369.012.e20190229

\section{Resumo}

As questões que envolvem o planejamento e a gestão do espaço urbano têm relação direta com o sistema de transportes. Existe uma interdependência entre crescimento urbano e a demanda por mobilidade, de maneira que deficiências de transportes interferem diretamente no cotidiano da população. Com base em métodos de análise espacial e no uso de ferramentas disponíveis em SIGs, avaliou-se para o caso de Belo Horizonte o nível de centralização e o poder de atração de viagens exercido pela área central, tendo como base os fluxos identificados nas últimas duas pesquisas "Origem e Destino". Diferentemente dos estudos que sugerem um forte processo de descentralização e rompimento do tradicional modelo centroperiferia, os resultados apresentados nesse trabalho indicam que a estrutura espacial de Belo Horizonte se manteve altamente concentrada na área central, embora novos fluxos pareçam convergir para novas centralidades no município.

Palavras-chave: Mobilidade. Centralidades. Área central. Ônibus.

\section{Abstract}

Issues involving the planning and management of urban spaces are directly related to the transportation system. There is an interdependence between urban growth and the demand for mobility, in such a way that transport deficiencies directly interfere with the daily life of the population. Based on spatial analysis methods and the use of tools available in GISs, the relationship between the level of centralization and the attractiveness exerted by the central area was evaluated in Belo Horizonte, based on trips identified in the last two surveys, origin and destination. Unlike the studies that suggest a strong process of decentralization and rupture of the traditional center-periphery model, the results presented in this paper indicate that the spatial structure of Belo Horizonte has remained highly concentrated in the central area, although new influxes seem to converge to new centralities in the city.

Keywords: Mobility. Centralities. Central area. Bus.

DAL é engenheira civil e doutora em Geografia, e-mail: daniela.lessa@ufop.edu.br

CL é geógrafo e doutor em Geografia, e-mail: carlosfflobo@gmail.com 


\section{Introdução}

Segundo Villaça (2017), especialmente a partir das últimas décadas do século passado, os deslocamentos populacionais de curta distância assumem papel preponderante na estruturação do espaço intraurbano, moldados pelas mediações dos conflitos na apropriação diferenciada do espaço urbano. As condições de mobilidade tornam-se decisivas na dinâmica de organização espacial, constituindo-se em objeto principal dos conflitos sociais. Para Castells (2003) o processo de produção do espaço ocorre pela conformação de uma cidade caracterizada pela conexão de diferentes lugares em uma mesma rede de interação simultânea, que reúne processos e pessoas em um ambiente global de interação. Nessa perspectiva, a cidade representa o lócus da mediação de relações entre processos econômicos, sociais políticos e culturais que modificam o espaço e colaboram de modo essencial na consolidação de redes densas e articuladas ao longo do território (Lefebvre, 1972). 0 espaço compõe às redes de deslocamento de pessoas e mercadorias (sistemas de mobilidade), à dimensão física territorial da cidade, onde se produzem formas de uso e apropriação (Haesbaert, 2004). Torna-se relevante, portanto, a necessidade de investigar a distribuição espacial dos fluxos de população, considerados em determinados recortes regionais. Ainda que esse trabalho envolva uma abordagem essencialmente analítica, o que pode suscitar limites à interpretação dos resultados, pode ser útil tanto à formulação de políticas de trânsito e tráfego quanto como input às ferramentas de gestão e ao planejamento urbano.

O município de Belo Horizonte, capital do estado de Minas Gerais/Brasil, segundo os dados do Censo Demográfico de 2010, tinha uma população residente de quase 2,5 milhões, distribuídos em área de apenas $330 \mathrm{~km}^{2}$. Essa elevada densidade demográfica, a exemplo do que ocorre em boa parte das capitais brasileiras, está associada à reprodução de inúmeras precariedades na provisão de acessibilidade e mobilidade urbanas, o que tem contribuído para o agravamento das situações de vulnerabilidade social e degradação ambiental. As condições de acessibilidade e mobilidade espaciais são caracterizadas por uma série de iniquidades, resultantes da estruturação de um espaço de circulação no qual o transporte individual historicamente foi privilegiado e as parcelas mais vulneráveis têm sido preteridas (Cardoso, 2007). Ainda que tenha havido queda quando comparados os dados das pesquisas "Origem e Destino" de 2002 e 2012 (Lobo \& Cardoso, 2018), o sistema de transporte atualmente ainda é centrado no modo ônibus (correspondendo a 98\% das viagens por transporte coletivo em 2012), com forte tendência radiocêntrica e diametral, o que eleva a probabilidade de retenções e congestionamentos no tráfego em torno da área central e pericentral.

Parte-se do suposto que a mobilidade urbana por ônibus, que se caracteriza como um serviço público para prover o deslocamento espacial de grandes volumes da população, seja pela necessidade de mão de obra ou para atender ao mercado de consumo de serviço e comércio, pode ser um indicador sensível à dinâmica da organização econômica regional, especialmente em relação ao nível de centralização e ao poder de atração da área central. De modo associado, a própria concentração de determinadas atividades econômicas, notadamente de serviços e comércio, atua na atração da demanda por viagens, o que reforça a atuação de forças centrípetas e dos modelos de circulação radiocêntrica, o que reforçaria um ciclo de concentração. Considerando o caso de Belo Horizonte, algumas questões são centrais: os dados das últimas décadas têm indicado aumento do nível de concentração das viagens para a área central do município? Há um rearranjo dos fluxos na escala intrarregional? A política de incentivo à descentralização, definida explicitamente em um dos objetivos do Plano Diretor de Belo Horizonte, instituído pela Lei 7.165 (Belo Horizonte, 1996), revogada pela Lei no 11.181 de 2019 (Belo Horizonte, 2019), tem representado mudanças recentes? Busca-se, dessa forma, avaliar a hipótese de queda do poder de atração da área central de Belo Horizonte, identificada por meio dos fluxos de viagens por ônibus nas duas últimas pesquisas "Origem e Destino" (2002 e 2012). Ainda que a metodológica apresentada neste trabalho seja de natureza essencialmente descritiva e exploratória, permite sintetizar, por meio de tabulações específicas e cartogramas, aspectos específicos sobre a relação entre os fluxos por ônibus e a dinâmica regional do município, apresentando informações potencialmente úteis à tomada de decisões e à formulação de políticas de gestão da mobilidade aos sistemas de transporte público. 


\section{Mobilidade, centro e centralidades urbanas}

A urbanização é um dos processos marcantes na contemporaneidade. As mudanças associadas à urbanização não são apenas dados isolados, mas representam mudanças profundas na organização social, que envolvem a prevalência de novos modos de vida. Como bem descreve Lefebvre (1972), a cidade pós industrialização representa a mediação de relações entre processos globais (econômicos, sociais políticos e culturais) e ritmos locais que modificam o espaço urbano e colaboram de modo essencial na consolidação de redes urbanas densas e articuladas ao longo do território.

Os problemas relacionados à mobilidade urbana, potencializados com a intensificação do processo de urbanização, são, em boa medida, reflexos diretos do acelerado processo de expansão e crescimento do tecido urbano, que resulta da elevada concentração espacial da população e das demandas de mobilidade em áreas específicas (Rodrigue et al., 2006). Litman (2017) afirma que as questões que envolvem o planejamento e a gestão do espaço urbano sempre estiveram relacionadas ao sistema de transportes. Existe, portanto, uma interdependência entre crescimento urbano e a demanda e oferta de transportes, de maneira que deficiências nos transportes interferem diretamente no cotidiano da população, exigindo diversas formas de intervenção do poder público. 0 crescimento urbano acelerado, a dispersão espacial, o aumento no número de automóveis nos centros urbanos, de congestionamentos e de acidentes de trânsito, as deficiências no transporte coletivo e o uso intensivo do solo são reflexos da dissociação entre os aspectos do planejamento urbano e de transporte que têm levado a uma deterioração da qualidade de vida da população nos centros urbanos (Schoenau \& Müller, 2017).

Contudo, o conceito de mobilidade é, ainda hoje, carregado de indefinições e imprecisões. Envolve as noções de movimento, deslocamento, mudança e transformação. Pode, todavia, assumir várias interpretações, como relacionada à mobilidade social, espacial e residencial (Cardoso, 2007). A própria expressão mobilidade urbana tem tido destaque e dado suporte teórico ao planejamento urbano e de transportes (Magagnin \& Silva, 2008), na influência da distribuição espacial (Chen et al., 2017) ou como indicador de mobilidade urbana sustentável (Costa et al., 2017). Como destaca Balbim (2016), o conceito de mobilidade é polissêmico e sistêmico, incluindo dimensões tanto da circulação, como da acessibilidade. É definida, ainda de acordo com esse autor, como o conjunto de motivações, possibilidades e constrangimentos que influenciam a projeção e realização dos deslocamentos de pessoas, bens e ideias. Assim, o conceito de mobilidade não se refere apenas ao melhor deslocamento de um ponto a outro do território (circulação) ou à existência de infraestrutura viária e de diversos modos de transporte (acessibilidade). Incorpora a circulação e a acessibilidade e "[...] trata de outro movimento, justamente o que permite ampliar as possibilidades de apropriação e uso coletivo e individual do espaço urbano [...]" (Barbosa, 2014, p. 198). Embora sejam conceitos correlacionados, dado que a mobilidade efetiva requer certo nível de acessibilidade ao sistema de transporte, não tem o mesmo significado e não apresentam necessariamente relação de causalidade direta. Não raro o baixo nível de acessibilidade não inibe a elevada demanda por mobilidade, especialmente em áreas periféricas com menor provimento de infraestrutura adequada (vias, terminais e pontos de embarque) e de oferta de meios de transporte, especialmente de natureza pública/coletiva. Não há, portanto, como demostrado por Lessa et al. (2019), uma relação direta entre a mobilidade e a acessibilidade ao sistema de transporte público.

No âmbito do planejamento de transportes, considera-se a mobilidade relacionada à capacidade de viajar, definindo o potencial de movimento (Handy, 1994); um termo qualitativo que representa a capacidade que um grupo de indivíduos tem para se deslocar a partir de uma área, que depende essencialmente da disponibilidade dos diferentes tipos de modos de transporte (Handy, 1994; Morris et al., 1979). O conceito está, portanto, relacionado com a capacidade de realização dos deslocamentos diários de uma determinada população no espaço. Refere-se não apenas à sua efetiva ocorrência, mas também à possibilidade ou facilidade dessas viagens (Cardoso, 2007). Para Vasconcellos (1996), o conceito de mobilidade envolve dois componentes: o desempenho do sistema de transportes e as características próprias do indivíduo (i.e., renda, emprego, gênero, idade, modo de transporte local), que diferenciam e determinam as condições individuais e coletivas em termos do deslocamento em áreas 
urbanas (Costa et al., 2017). A mobilidade configura-se, nesse aspecto, como a necessidade por transporte, moldada pelo modo de vida da população (Raia, 2000). Pode ser considerada como um importante recurso social e articulador na sociedade, uma vez que está diretamente relacionada ao movimento de pessoas entre diferentes hierarquias socioespaciais (Costa et al., 2017). Wiel (2005) afirma que a mobilidade depende mais da natureza da atividade que será realizada (motivo do deslocamento), traduzida pelo interesse social envolvido, no porquê o indivíduo se desloca. Para o autor, a compreensão das estratégias de localização das pessoas (habitação) e das instituições (equipamentos e empresas) é essencial para a análise e o entendimento da mobilidade.

As pessoas raramente estão localizadas nas áreas onde as atividades econômicas ocorrem. Dessa forma, os sistemas de transporte tornam-se necessários para interligar a oferta e a demanda, de modo que os desejos das pessoas se manifestem pelo acesso a bens e serviços. As relações econômicas e as conexões entre as áreas também influenciam as características da infraestrutura de transportes e no fluxo de tráfego e, de forma inversa, a facilidade ou não de deslocamento, o volume de tráfego e as distâncias percorridas têm efeitos significativos sobre a natureza e a organização das atividades econômicas. Nesse contexto, vários trabalhos deixam de focar apenas em uma abordagem social "estática" para postular um "novo paradigma de mobilidades" (Button \& Nijkamp, 1997; Shaw et al., 2008). A relação entre a estrutura urbana e os transportes é resumida por Calvet (1970), que considera ser

[...] difícil chegar ao conhecimento dos transportes urbanos sem passar antes pelo estudo da estrutura urbana sobre a qual eles vão se desenvolver. 0 problema dos transportes não é um problema que pode se resolver em si mesmo. Ele atua num determinado cenário, a cidade, então é preciso conhecer a fundo suas características para determinar não somente a demanda por transportes como também os meios mais adequados para satisfazê-la, o que está exatamente relacionado com as peculiaridades da estrutura física da urbe. (Calvet, 1970 apud Campos, 2013, p. 8)

As relações entre o transporte e o espaço produzido podem ser estudadas em diferentes escalas. As grandes infraestruturas participam da (re)organização das redes urbanas e do equilíbrio territorial nas escalas nacional e internacional; na escala regional, as investigações acerca do impacto dessas infraestruturas sobre o território podem tratar das questões relacionadas à análise da oferta e do nível de serviço, bem como à administração pública; já o estudo local permite verificar a relação da infraestrutura com a produção e transformação do espaço urbano (Grillet-Aubert et al., 2001). Logo, os conceitos de mobilidade e sua relação com a forma urbana se tornam centrais à compreensão da dinâmica e da heterogeneidade da organização espacial. Como ressalta Berman (2007), é na cidade contemporânea que os anseios de mobilidade social e espacial dos indivíduos e grupos são traduzidos. De fato, a circulação de bens e pessoas se tornou decisiva com o advento da cidade industrial, de maneira especial, quando o urbano se tornou uma condição de produção da vida social em conjunto (Barbosa, 2014). Na literatura é reconhecido que o sistema de transportes tem influência direta nos custos de produção, nos fluxos de comércio, no bem-estar social e na articulação de áreas de mercado, tendo um papel essencial no crescimento e desenvolvimento econômico das cidades (Mitra \& Saphores, 2016). Há, portanto, uma estreita relação entre estratégias e políticas de transporte, que compreende um círculo "vicioso" envolvendo o uso do solo, o intercâmbio de atividades, o transporte, a acessibilidade e a mobilidade (Rodrigue et al., 2006).

Zhong et al. (2014), tomando os deslocamentos da população como uma proxy para a dinâmica e interação espacial, identifica alguns elementos, dados como essenciais da estrutura espacial urbana: os hubs, definidos como áreas que conectam os espaços por onde os estoques urbanos são transferidos, atuando dentro da estrutura urbana como pontes espaciais entre os diferentes bairros; o centro, definido pelos autores como a área mais relevante, onde se acumulam os estoques urbanos; e as centralidades, referentes aos limites socioeconômicos gerados por localizações determinadas com base na concentração de viagens. São diversos trabalhos que tratam os centros urbanos, sua pluralidade e importância. Seja enquanto elementos (centros e subcentros) ou enquanto processos de alteração da estrutura urbana (centralização e descentralização), o espaço urbano é uma "[...] forma pura: o ponto de encontro, o lugar de uma reunião, a simultaneidade [...]" (Lefebvre, 2008, p. 110). Como os centros são 
áreas de maior concentração de oportunidades, terão como principal característica a atração de viagens por motivos diversos (i.e., trabalho, compras, serviços, educação e lazer). Assim, torna-se relevante relacionar a mobilidade urbana com a dinâmica da organização regional, especialmente no que tange ao poder de atração da Área Central, de forma a verificar em que medida a mobilidade pode ser útil na identificação do Central Business District (CBD) tradicionais.

De acordo com Batty (2005), é imprescindível a compreensão da estrutura urbana, do arranjo espacial dos hubs, dos centros e das centralidades (ou subcentros) e de como os indivíduos interagem com essas estruturas. As estruturas monocêntricas e policêntricas há muito são estudadas e modeladas. Segundo Wilson (2014), o modelo dominante da cidade industrial é baseado em uma estrutura monocêntrica. Porém, diversos autores já consideram que essa estrutura já não representa mais a organização urbana contemporânea (Kneib \& Silva, 2014). De acordo com Kloosterman \& Musterd (2001), as cidades contemporâneas, por serem mais complexas, exibem padrões de policentralidade que requerem um estudo específico para a sua compreensão. McMillen (2001) justifica que as regiões metropolitanas se tornaram cada vez mais descentralizadas e os CDBs tradicionais passaram a apresentar uma proporção muito inferior de oportunidades de empregos, serviços e comércios do que no passado. Bertaud (2004, p. 9, tradução dos autores) acrescenta que "[...] nenhuma cidade é 100\% monocêntrica, e raramente é 100\% policêntrica [...]. Algumas cidades são monocêntricas dominantemente. Outras são predominantemente policêntricas e muitas estão no meio - são híbridas" ${ }^{1}$. À medida que cresce em tamanho, a estrutura original monocêntrica pode evoluir e se espalhar pelo tecido urbano e direção à estrutura policêntrica. Para esse mesmo autor, as estruturas mono e policêntricas têm a mesma origem, porém observadas em momentos diferentes de seu processo evolutivo (Bertaud, 2004).

Para Rochefort (1998), a cidade é constituída pelo conjunto de centros necessários para suprir as demandas das atividades econômicas e da população. Para esse mesmo autor, a diferença entre os centros acarreta as formas de interdependência, resultando na passagem da noção de centro para a noção de rede de centros. Botechia (2001) afirma que a nova circulação dos fluxos, ao alterar a influência do centro "antigo", desconstrói a lógica hierárquica da cidade tradicional, dependente da existência de um centro estável e permanente. Corrêa (1995) complementa as ideias de Lefebvre (2008) e Bertaud (2004), ao considerarem a cidade capitalista como palco de uma série de processos sociais, entre eles a acumulação de capital e a reprodução social, consideram que os elementos que viabilizam, ao longo do tempo, a criação de funções e formas espaciais, não são excludentes entre si, podendo ocorrer simultaneamente na mesma cidade. Villaça (2017) também reforça a noção que toda aglomeração espacial humana desenvolve um centro principal. Ainda sobre esse aspecto, Vargas (2006) afirma que a ideia de cidade está associada a de concentração e busca em Lefebvre (2008) um suporte para sua definição. 0 termo "concentração" traz embutida a definição do centro. As próprias cidades são centro, uma vez que são fundamentalmente pontos de convergência. A densidade de ocupação, contudo, não é uniforme, havendo pontos de convergência e concentração sempre farão parte dessa ocupação, independente da escala analisada (Vargas, 2006). Villaça (2017) não descarta o conceito de cidades "polinucleadas", apresentado por Gottdiener (1993), porém, defende que, embora em algumas aglomerações o crescimento espacial não se faça mais a partir de um único centro hegemônico, "existe um e apenas um, que é o centro principal", onde há uma maior concentração de oportunidades, e os subcentros, definidos pelo autor como "[...] aglomerações diversificadas e equilibradas de comércio e serviços, que não o centro principal." (Villaça, 2017, p. 245, 293). Ainda conforme esse autor, os subcentros atendem aos mesmos requisitos de acesso do centro principal. O primeiro cumpre os requisitos apenas para uma parte da cidade. 0 centro principal envolve toda a cidade. Embora este trabalho seja motivado por questões relativamente recentes de transformação urbana, trata essencialmente de uma questão da produção do espaço urbano, que não é aleatória e nem natural, relacionada à organização heterogênea dos fluxos, refletindo as contradições sociais.

\footnotetext{
1 "No city is ever 100\% monocentric, and it is seldom 100\% polycentric [...]. Some cities are dominantly monocentric, others are dominantly polycentric and many are in between." (Bertaud, 2004, p. 9).
} 
De acordo com Zhong et al. (2014), ao longo do último meio século, várias técnicas para decompor espacialmente dados agregados e para agregar espacialmente dados individuais. Uma parte importante desse desenvolvimento tem sido o surgimento e aprimoramento das tecnologias disponíveis nos SIGs, notadamente aquelas aplicadas à análise do sistema de transporte. Nas últimas décadas, foram vários os avanços de softwares, hardwares e sistemas operacionais que permitem aos pesquisadores a manutenção de grandes bancos de dados e a realização de análises sofisticadas. A melhoria nas capacidades de armazenamento e processamento permitiu que muitos modelos de transporte fossem incorporados aos programas específicos, além de se tornarem mais visuais. Muitas pesquisas na área têm sido publicadas, incluindo os textos de Thill (2000) e Gutiérrez et al. (2010). Há um número crescente de análise das redes e dos fluxos nas cidades utilizando dados de circulação de pessoas e mercadorias e análise espacial. Muitos novos métodos estão sendo aplicados a novos problemas. Por exemplo, os padrões de localização das atividades comerciais são utilizados de forma recorrente nos estudos da estrutura espacial urbana (Anderson \& Bogart, 2001; Giuliano \& Small, 1991; McDonald, 1987). Recentemente, os padrões de movimentos dos indivíduos têm sido utilizados nesses estudos (Zhong et al., 2014). A identificação da estrutura espacial urbana, com base nos dados de deslocamento da população e de aplicação de estatísticas espaciais, é central para se estimar os impactos sociais, econômicos e ambientais resultantes dos padrões de atividade e de viagens (Zhong et al., 2014). Ademais, essa compreensão tornou-se um importante instrumento para o planejamento urbano e para a gestão da mobilidade e da acessibilidade, à luz da estrutura de utilização do espaço nas cidades (Lessa et al., 2018).

Uma questão apresentada por alguns pesquisadores, explorada especificamente neste trabalho, é a possibilidade de avaliar o poder de atração de viagens para a área central, dado um recorte regional urbano preestabelecido. Assim, com base na utilização de dados secundários e de ferramentas de análise espacial, busca-se averiguar em qual medida a mobilidade, aqui representada pelo número de viagens por ônibus entre os campos de Belo Horizonte, identificada nas últimas duas pesquisas "Origem e Destino", permite avaliar o poder de atração de viagens exercido pela área central (CBD), definido como a zona urbana, planejada, limitada pela Avenida do Contorno, bem como o crescimento de fluxos para novas centralidades no município. Trata-se, como demostrou Tonucci (2009), de uma área que recebeu tratamento especial pelo Plano Original, apresentando a maior concentração de serviços e atividades comerciais e melhor dotação de infraestrutura. Segundo a OD de 2012, o acesso a bens e serviços da área central de um modo geral é responsável por 31,4\% dos deslocamentos, sugerindo ainda uma relação de dependência entre o CBD e as demais unidades espaciais da capital.

\section{Base de dados, recortes/unidades espaciais e procedimentos metodológicos}

Os dados utilizados na produção da matriz de viagens por ônibus internas a Belo Horizonte foram extraídos das pesquisas "Origem e Destino" de 2002 e 2012 (OD 2002 e 2012). Trata-se de um levantamento amostral periódico, cuja penúltima e última versões foram elaboradas e disponibilizadas, respectivamente, pela Fundação João Pinheiro (FJP) e pela Agência de Desenvolvimento da Região Metropolitana de Belo Horizonte (Agência RMBH), órgãos ligados ao Governo do Estado de Minas Gerais. Para fins de processamento e análise, foram utilizados como unidades espaciais as regionais administrativas e os denominados campos (Figura 1), que compreendem agregações de áreas homogêneas (menor nível de desagregação espacial utilizado nas ODs). Os campos são unidades espaciais adequadas para se estabelecer amostras mínimas das condições sociais e econômicas locais, que, em geral, coincidem com o recorte de bairros ou pequenos grupos de bairros de Belo Horizonte, tornando mais acessível a gestão da informação. Em Belo Horizonte, na pesquisa OD/RMBH de 2012, foram discriminados 120 campos, distribuídos nas nove regionais administrativas: Barreiro, Oeste, Centro-Sul, Noroeste, Leste, Pampulha, Nordeste, Norte e Venda Nova (Figura 1). A fim de uniformizar as unidades espaciais de análise, os campos da OD 2002 foram compatibilizados com a base da OD 2012, tendo como 
referência as AHs relativas ao recorte de 2002, sobrepostas aos Campos na divisão de 2012, considerando a localização do centroide como ponto de ajuste.

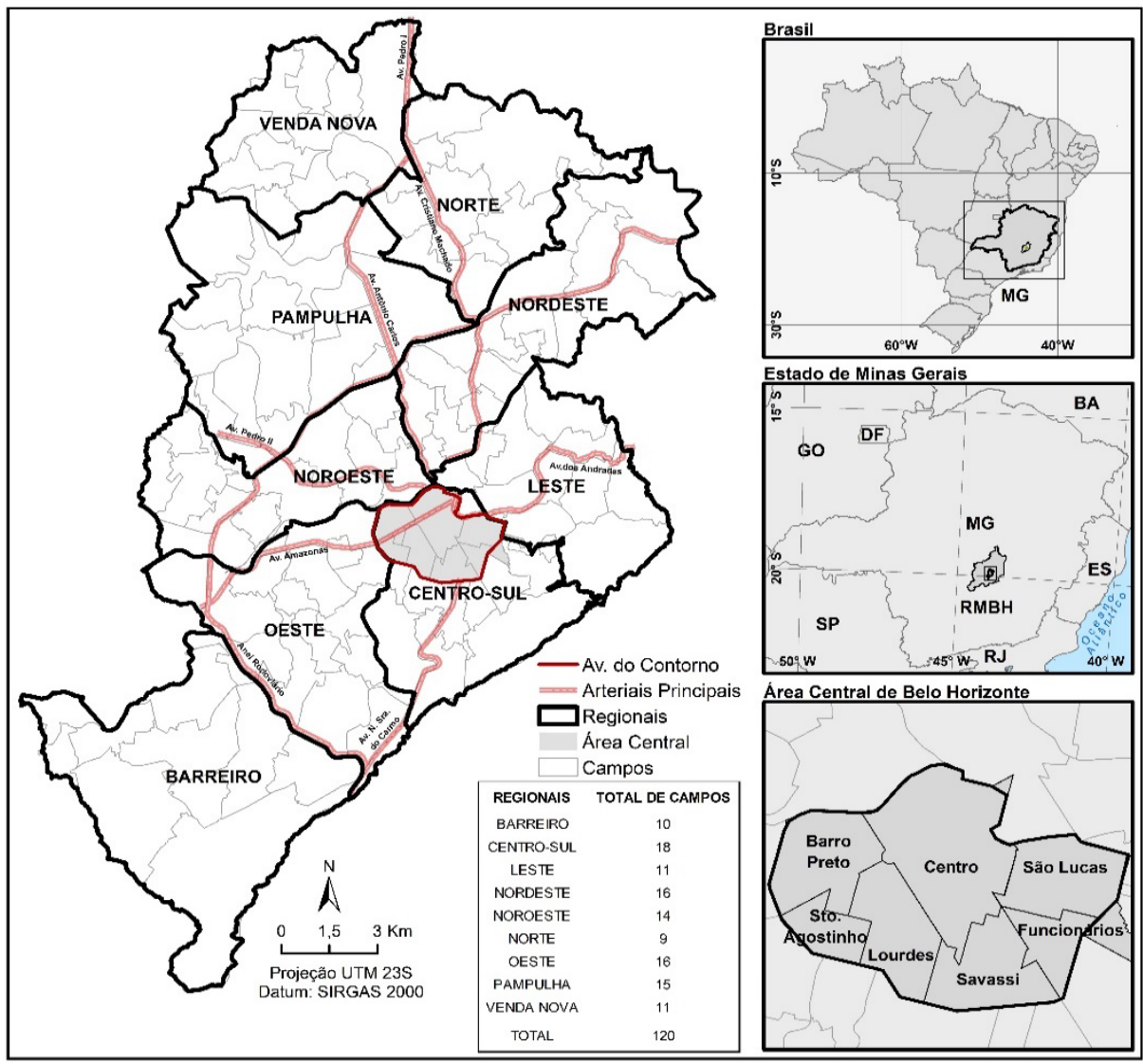

Figura 1 - Campos, regionais administrativas, área central e principais vias arteriais de Belo Horizonte/MG. Fonte dos dados: Elaboração própria. Base de dados digital das Unidades Territoriais (PRODABEL).

Com o objetivo de avaliar a dinâmica da organização regional ao longo de dez anos e investigar a manutenção da importância do papel do centro da capital, conforme verificado no trabalho de Lessa et al. (2018), foram analisadas as viagens por ônibus dentro do município de Belo Horizonte, discriminadas em internas e externas às regionais (nomeadas neste trabalho como intrarregionais e inter-regionais, respectivamente) e, de forma mais específica, as viagens para a área central de Belo Horizonte, delimitada pela zona interna à Avenida do Contorno. Essa área central é composta por sete campos, que são: Barro Preto, Centro, Funcionários, Lourdes, Santo Agostinho, São Lucas e Savassi, estabelecidos por Belo Horizonte (2006) e apresentados na Figura 1. Os critérios para seleção dos fluxos utilizados nesse trabalho, necessários para a construção da matriz de origem e destino, estão indicados no Quadro 1.

Quadro 1 - Critérios para a seleção dos fluxos (OD 2002 e 2012)

\begin{tabular}{|c|c|}
\hline Variáveis & Critérios \\
\hline Campos de Origem & Todos de Belo Horizonte (Base OD 2012) \\
\hline Campos de Destino & Todos de Belo Horizonte (Base OD 2012) \\
\hline Modos de Transporte & Residência* \\
\hline Motivo Origem & Compras, Escola, Trabalho, Negócios, Lazer, Saúde e Refeição \\
\hline Motivo Destino & Dia \\
\hline Período de Análise & \\
\hline
\end{tabular}

* Nota-se que do campo Campus da UFMG não partem viagens com origem "Residência" e, portanto, não apresentará valores nos cartogramas apresentados nas análises. Fonte: Elaboração própria. 
As viagens intrarregionais (2002 e 2012) foram identificadas pela seleção daquelas com origem e destino nos campos pertencentes à uma mesma regional. Para as viagens inter-regionais, foram selecionadas aquelas com origem em algum campo da regional e destino em outro localizado em uma regional distinta. Por fim, as viagens à área central (AC) foram determinadas por aquelas com origem em qualquer campo não pertencente à $\mathrm{AC}$ e destino aos campos internos à Avenida do Contorno. As análises, conforme indicado nos cartogramas da próxima seção, foram realizadas com base nos percentuais de viagens, por ônibus, inter e intrarregionais em relação ao total selecionado. Com o objetivo de verificar o peso que o à $\mathrm{AC}$ afigura em cada campo e quanto ele é prevalente (ou não) em relação ao fluxo intrarregional, foi proposto um indicador, nomeado Índice de Atração da AC ( $I D A_{A C}$ ), para os anos 2002 e 2012 (Equação 1).

$$
I D A_{A C}=\frac{V_{A C_{i}}}{V_{I N_{i}}}(1)
$$

em que:

- $V_{A C_{i}}$ : número de viagens com origem no i-ésimo campo e destino à $\mathrm{AC} ; \mathrm{e}$

- $V_{I N_{i}}$ : número de viagens intrarregionais.

No que tange aos possíveis resultados da Equação 1, os valores iguais a 1 indicam fluxos à AC e intrarregionais equivalentes; valores maiores do que 1, a prevalência dos fluxos à $\mathrm{AC}$; e, por fim, os valores menores que 1 , o predomínio dos fluxos intrarregionais.

Também foi utilizada uma medida de estatística espacial: a distância média ponderada $\left(D M_{\omega}\right)$. Trata-se de um indicador que avalia o nível de concentração/dispersão espacial com base em um conjunto de vetores espaciais, definidos pelos pontos de coordenadas entre os campos de origem e destino de cada viagem. No caso desta pesquisa, os pesos foram considerados pelo volume de viagens entre os campos de origem e destino (campos da AC), indicados na Equação 2.

$$
D M_{\omega}=\frac{\sum\left(d_{i}^{*} \omega_{i}\right)}{\sum \omega}
$$

em que,

- $\omega_{i}$ : peso do i-ésimo vetor de deslocamento.

- $d_{i}$ : distancias do i-ésimo vetor de deslocamento.

Ao comparar o valor do $D P_{\omega}$ nos dois períodos, tem-se, respectivamente, uma medida de concentração/dispersão espacial das viagens, consideradas as distâncias lineares (euclidianas). Trata-se, nesse caso, de uma proxi de distância, não de um indicador de eficiência no deslocamento, capaz de aferir a trajetória ou a velocidade real de deslocamento, haja vista que as distâncias em cada percurso são superiores aos valores lineares utilizados.

\section{A atração de viagens da área central de Belo Horizonte: análise e interpretação dos resultados}

De acordo com os dados das pesquisas OD de 2002 e 2012, houve um aumento geral do fluxo de viagens dentro do limite territorial de Belo Horizonte. Na década, o volume total de viagens passou de 3,5 para 6,0 milhões. No entanto, esse crescimento ocorreu de maneira bem distinta nos diferentes modos de transporte e nas regionais administrativas do município. No que tange às viagens por ônibus, o número reduziu, passando de cerca de 1,4 milhões $(40,2 \%$ do total) para 1,2 milhões $(21,0 \%)$. 
Considerando apenas as viagens filtradas neste trabalho, entre 2002 e 2012 passaram de cerca de 680 mil para 600 mil. Ao avaliar distribuição por regionais, verifica-se que os fluxos inter-regionais continuam como os mais relevantes, embora, proporcionalmente, a tendência geral tenha sido de queda na participação entre 2002 e 2012. As regionais que apresentaram maiores reduções desses fluxos foram Barreiro, Centro-Sul, Venda Nova e Norte (com reduções acumuladas de 13,6\%; 9,4\%; 7,6\%; e 6,0\%, respectivamente, entre 2002 e 2012), conforme indicado na Figura 2. Como esperado, na regional Centro-Sul, onde está localizada a AC, os fluxos para outras regionais são menos expressivos (em 2012, eram inferiores a $25 \%$ ).

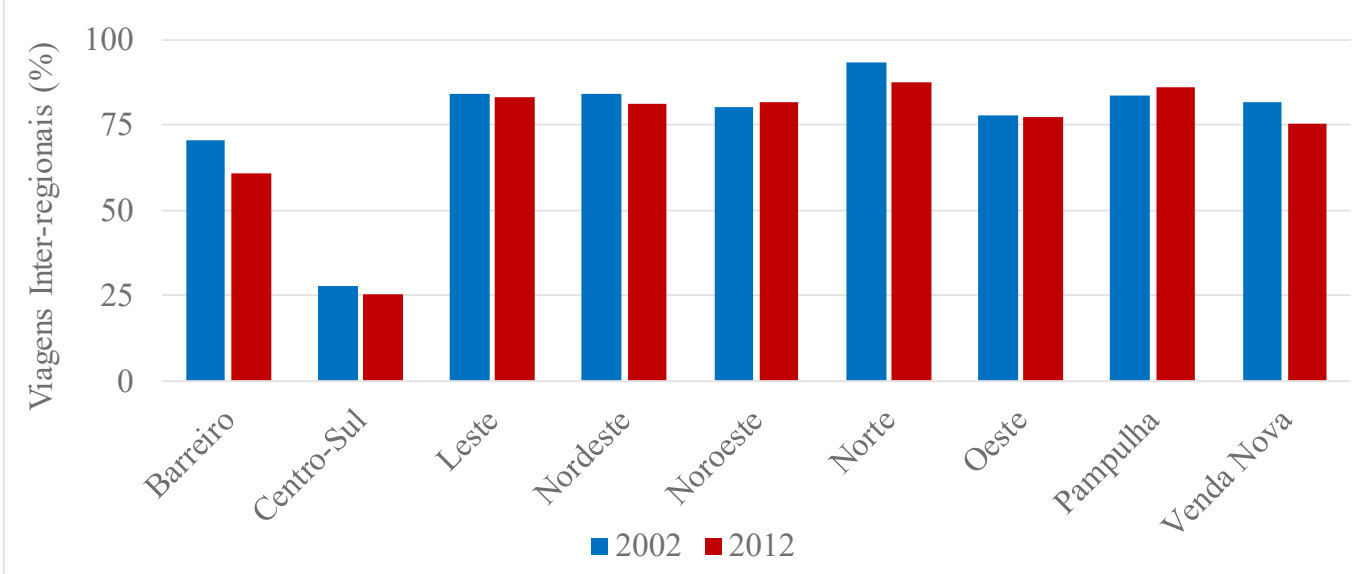

Figura 2 - Viagens inter-regionais por ônibus em Belo Horizonte/MG (2002 e 2012). Fonte dos dados: Elaboração própria. Base digital das Pesquisas OD (2002 e 2012).

De acordo com o representado na Figura 3a, em 2002, um total de dezoito campos apresentava mais de $40 \%$ das viagens intrarregionais por ônibus. Esse número passou para vinte e quatro na década seguinte (Figura 3b), dos quais dezesseis fazem parte da regional Centro-Sul; quatro da regional Barreiro; um de cada uma das regionais Noroeste, Nordeste e Venda Nova. Esses números corroboram os estudos de Lessa et al. (2018), que identificaram em Belo Horizonte um padrão espacial bem definido no entorno da AC. Nota-se, porém, que embora a AC continue exercendo um papel importante na definição da estrutura espacial da capital, novas centralidades ganham força de atração e se consolidam regionalmente. A análise dos cartogramas da Figura 3c e 3d também permite verificar a manutenção da prevalência dos fluxos inter-regionais de ônibus em 2002 e 2012, respectivamente. Em 2002, cem campos apresentavam mais de $60 \%$ das viagens por ônibus, com destino aos campos de outras regionais (Figura 3b). Em 2012, passou para noventa e cinco (Figura 3d). Ademais, nota-se que grande parte desses campos estão distribuídos preferencialmente no entorno dos grandes eixos viários municipais e intermunicipais (i.e., Via Expressa à oeste e as Avenidas Antônio Carlos, Cristiano Machado e dos Andradas ao norte, nordeste e leste, respectivamente, e o Anel Rodoviário) o que facilita o fluxo inter-regional e para o centro. 
2002

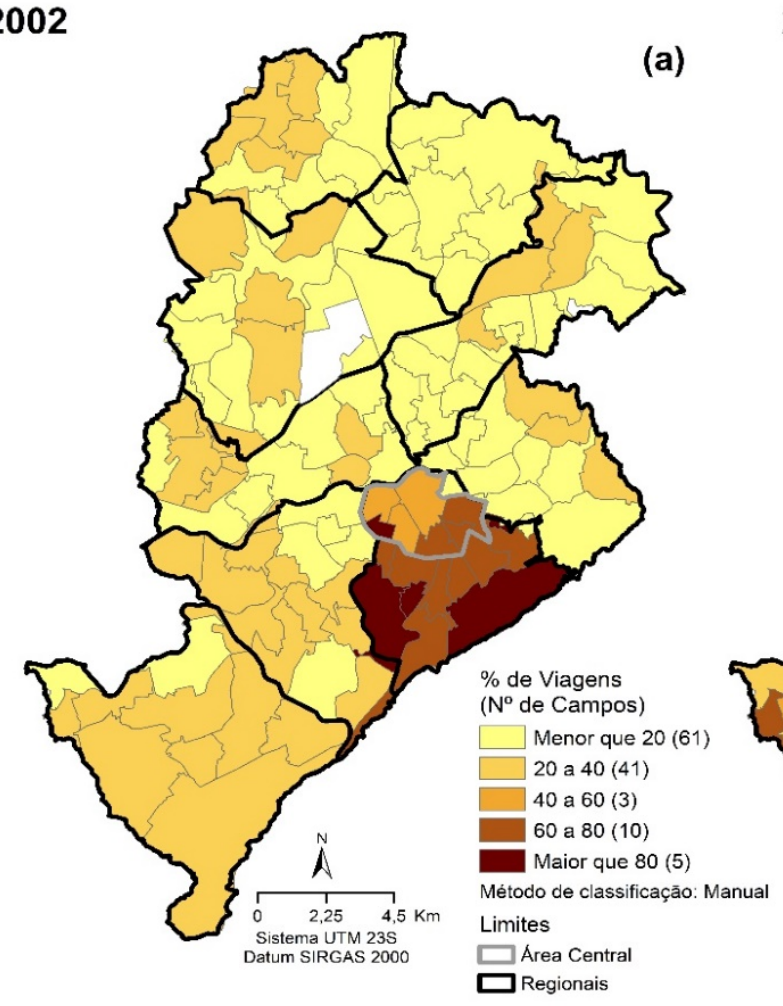

2002

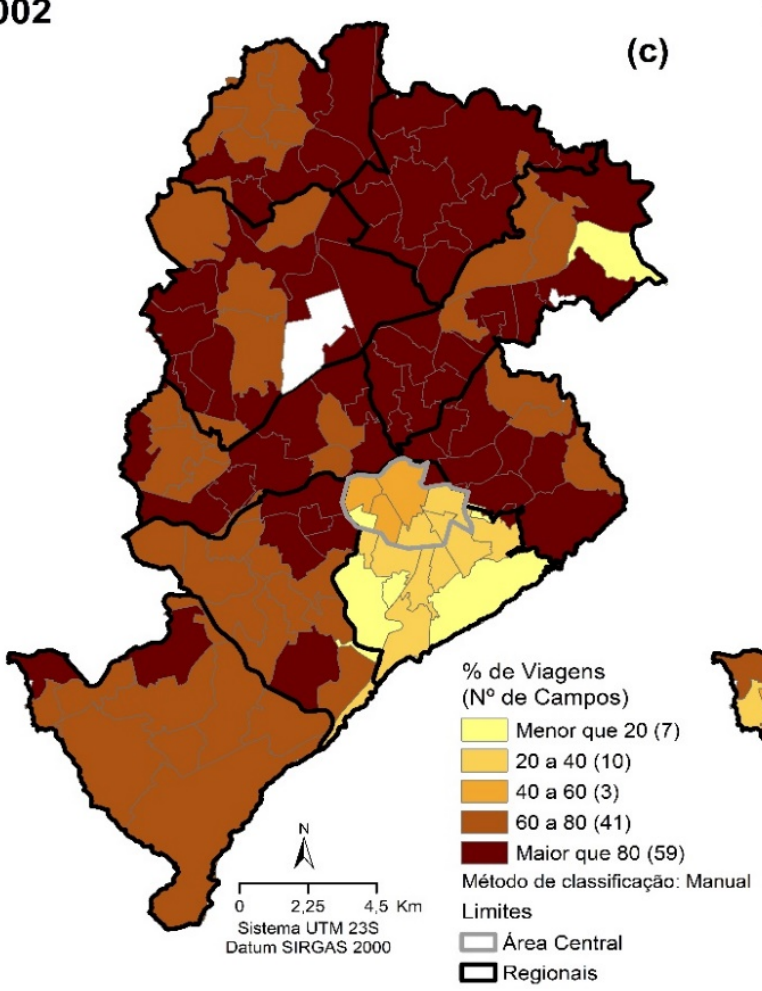

2012

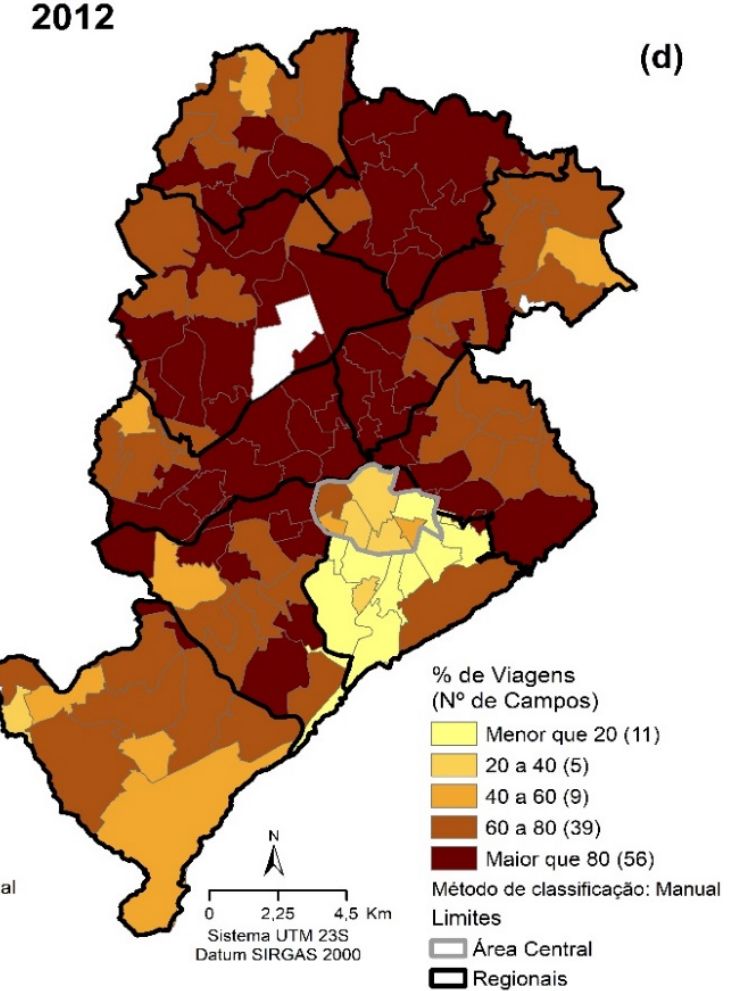

2012 (b)

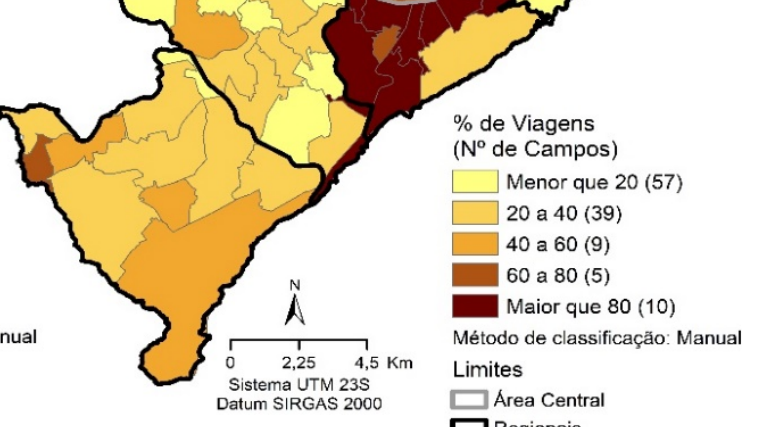

$\mathrm{N}^{\circ}$ de Campos)

$\square$ Menor que 20 (57)

40 a $60(9)$

Maior que $80(10)$

Método de classificação: Manual

$\square$ Area Central

$\square$ Regionais

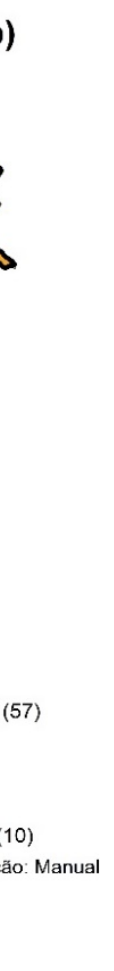

(d)

Figura 3 - Fluxos por ônibus em Belo Horizonte/MG: Intrarregionais 2002 (a) e 2012 (b), Inter-regionais 2002 (c) e 2012 (d). Fonte dos dados: Elaboração própria. Base digital das Pesquisas OD (2002 e 2012).

A análise do Índice de Atração à Área Central ( $\left.I D A_{A C}\right)$, que representa a relação entre os fluxos à AC e os intrarregionais, permite verificar que nos dois anos analisados, em boa parte das regionais prevalece o fluxo em direção à AC ( ${ }^{I D A_{A C_{\text {matio }}}<1}$, em laranja na Tabela 1) quando comparados aos demais, à exceção das regionais Centro-Sul e Barreiro, no ano de $2012\left({ }^{I D A_{A C_{\text {metio }}}<1}\right.$, em verde na Tabela 1). Na regional 
Centro-Sul, esse resultado já era esperado, uma vez que abrange a AC, principal zona de atração de viagens da capital. Já a regional Barreiro é caracterizada pelos importantes subcentros de comércio, empregos e serviços além de concentrar, juntamente com os municípios de Betim e Contagem, a produção industrial da metrópole.

Tabela 1 - Diferença entre os $I D A_{A C}$ médios por regionais de Belo Horizonte/MG (2002 e 2012)

\begin{tabular}{|c|c|c|c|}
\hline Regionais & $I D A_{A C_{\text {meditio }}}(2002)$ & $I D A_{A C_{\text {medio }}}$ (2012) & Diferença (\%) \\
\hline Barreiro & 1,45 & 0,97 & $-32,80$ \\
\hline Centro-Sul & 0,80 & 0,75 & $-5,80$ \\
\hline Leste & 4,45 & 4,45 & $-0,10$ \\
\hline Nordeste & 3,56 & 3,64 & 2,30 \\
\hline Noroeste & 3,02 & 4,15 & 37,10 \\
\hline Norte & 9,22 & 3,31 & $-64,10$ \\
\hline Oeste & 2,26 & 2,54 & 12,20 \\
\hline Pampulha & 3,05 & 4,26 & 39,70 \\
\hline Venda Nova & 3,60 & 1,84 & $-48,80$ \\
\hline
\end{tabular}

Fonte dos dados: Elaboração própria. Base digital das Pesquisas OD (2002 e 2012).

Para esses casos, foi realizada a análise da frequência dos fluxos para identificar quais campos de cada uma dessas regionais atraem e produzem mais viagens por ônibus (Figura 4). Na regional Barreiro, o campo que mais atrai fluxos internos é o Barreiro de Baixo, onde está localizada a estação Barreiro, a principal estação de integração BHBUS (Sistema de Transporte Coletivo de Belo Horizonte) e a Mannesmann/Vallourec. Já os campos que mais produzem viagens são o Vale do Jatobá, ocupado em grande parte por assentamentos habitacionais, produzindo viagens majoritariamente residenciais, e Santa Helena, onde está localizada a Estação Diamante, uma das seis estações de integração da capital. Na regional Centro-Sul, o campo que mais atrai fluxos internos é o Centro, o mais importante polo comercial e de serviços da capital, e o que mais produz é o Favela da Serra, abrigando população com menor poder aquisitivo, que utiliza recorrentemente o modo coletivo por ônibus.

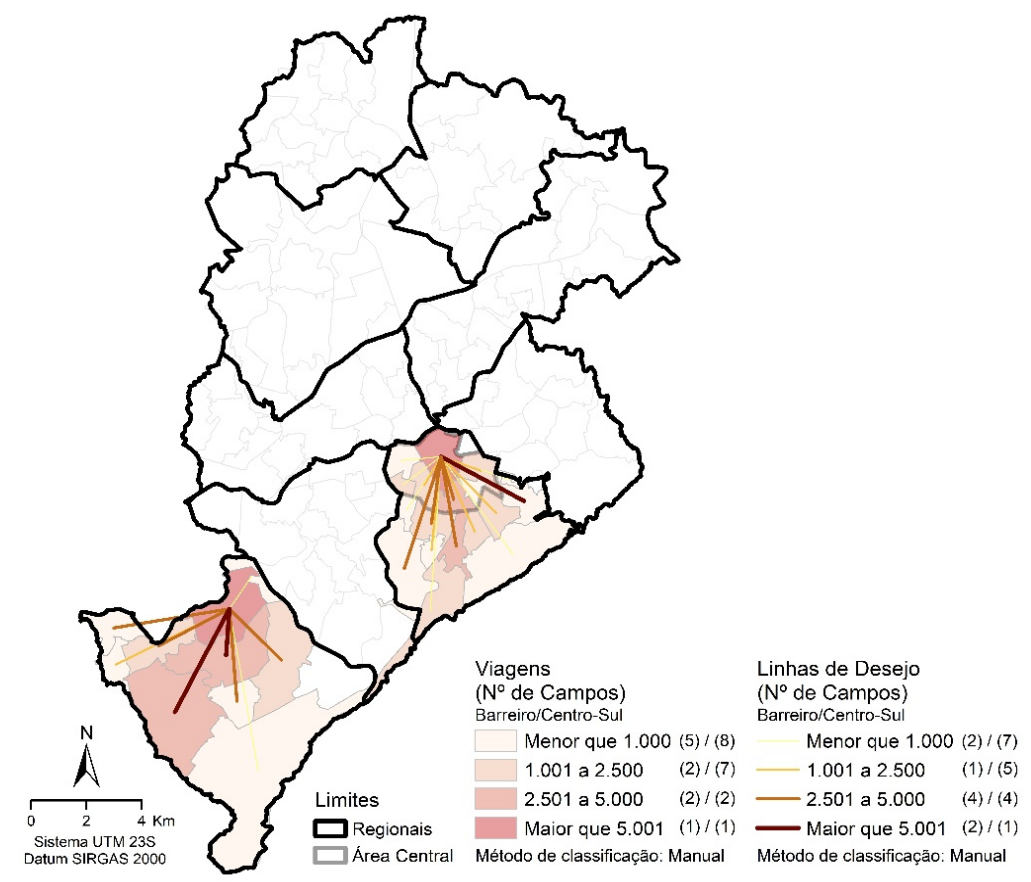

Figura 4 - Frequência de viagens intrarregionais nos Campos Barreiro e Centro-Sul (2012). Fonte dos dados:

Elaboração própria. Base digital das Pesquisas OD (2002 e 2012). 
Ainda com base na observação da Tabela 1 e da Figura 5, é possível confirmar a predominância existente dos fluxos ao CBD sobre os fluxos intrarregionais (valores maiores do que 1). Porém, nota-se o aumento dos fluxos intrarregionais entre 2002 e 2012, representado pela redução média de 17,5\% nos $I D A_{A C}$. Cinco regionais apresentaram uma redução percentual entre os $I D A_{A C}$ médios dos anos de $2002 \mathrm{e}$ 2012, apontando o aumento das viagens intrarregionais em detrimento das viagens à AC, sendo três os mais expressivos, Norte, Venda Nova e Barreiro. De forma inversa, quatro regionais apresentaram um aumento percentual dos $I D A_{A C}$ médios dos anos de 2002 e 2012, indicando o aumento das viagens à AC em detrimento das viagens intrarregionais, a exemplo das regionais Noroeste e Pampulha.
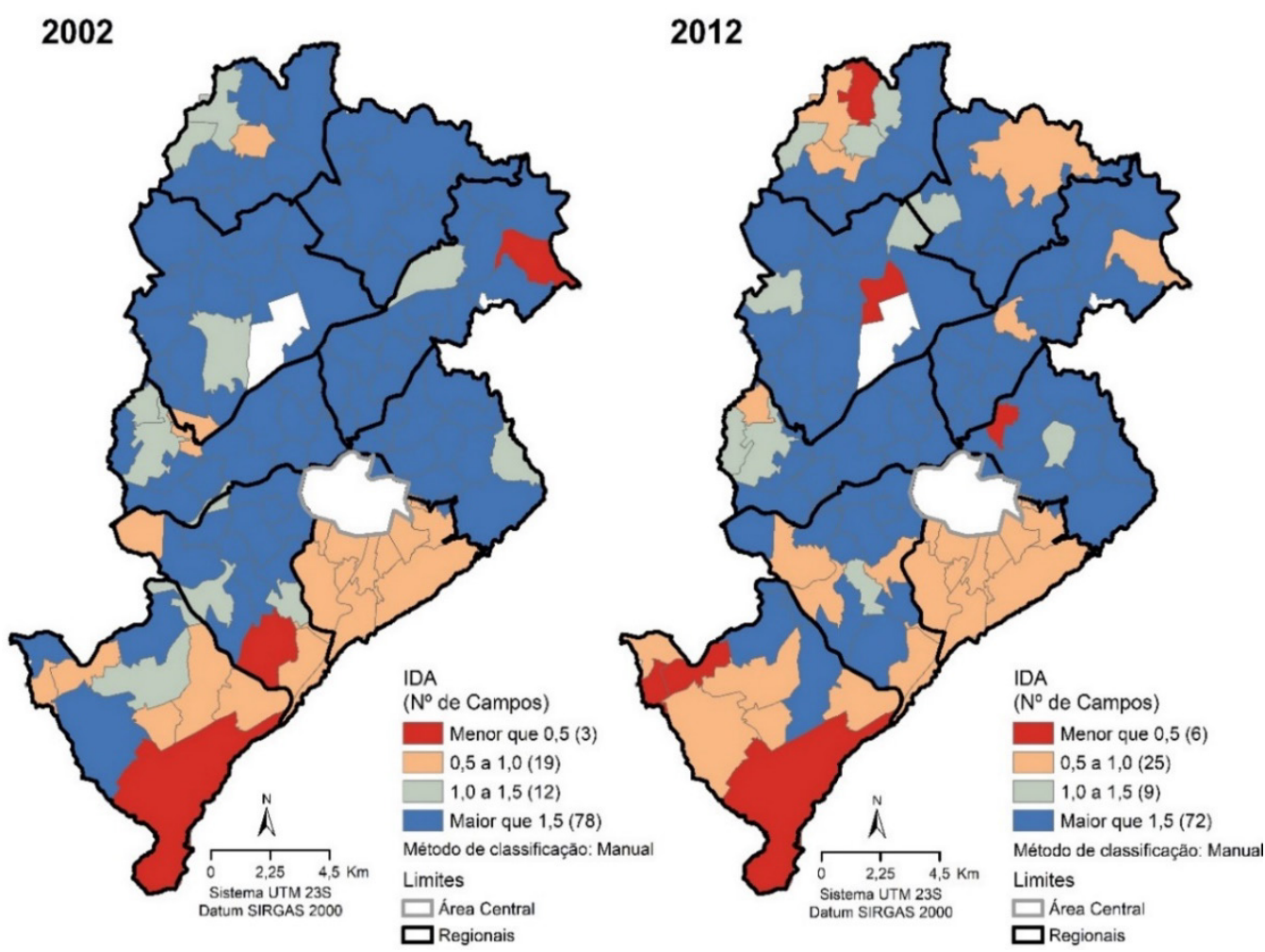

Figura 5 - Índice de Atração da AC de Belo Horizonte/MG (2002 e 2012). Fonte dos dados: Elaboração própria. Base digital das Pesquisas OD (2002 e 2012).

$\mathrm{Na}$ década, as viagens por ônibus com destino à AC passaram de cerca de 305 mil para 260 mil. Em geral, como representado nos cartogramas da Figura 6, essa redução foi relevante em todo o município, principalmente nas regionais onde houve maior incremento no fluxo intrarregional: Norte, Barreiro e Venda Nova. Em contrapartida, observou-se um aumento dos fluxos no Noroeste e Pampulha, cujo aumento foi mais expressivo. Todas essas evidências parecem confirmar a hipótese de "cidade fractal", caleidoscópica e polinucleada, sugerido por Soja (2000), Guimarães et al. (2005) e Tonucci (2009). Ademais, assim como observado nos fluxos inter-regionais, grande parte dos campos onde predominam os fluxos à AC está distribuída preferencialmente no entorno dos grandes eixos viários da capital, induzindo o fluxo inter-regional e para o centro.

Ao analisar os vetores que representam as viagens por ônibus destinadas à $\mathrm{AC}$, as distâncias médias ponderadas ( $D M_{\omega}$ ) dos fluxos com origem cada um dos campos, ponderada pelos fluxos de 2002 e 2012

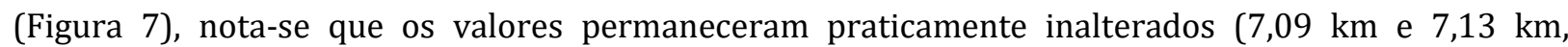
respectivamente). Embora vários vetores de deslocamento para fora do eixo central tenham ganhado força, os fluxos para área central, especialmente aqueles de origem no pericentro continuam relevantes. Esses indicadores permitem inferir que a concentração espacial do fluxo para a AC não se alterou substancialmente, ainda que a mobilidade inter-regional não seja irrelevante. 

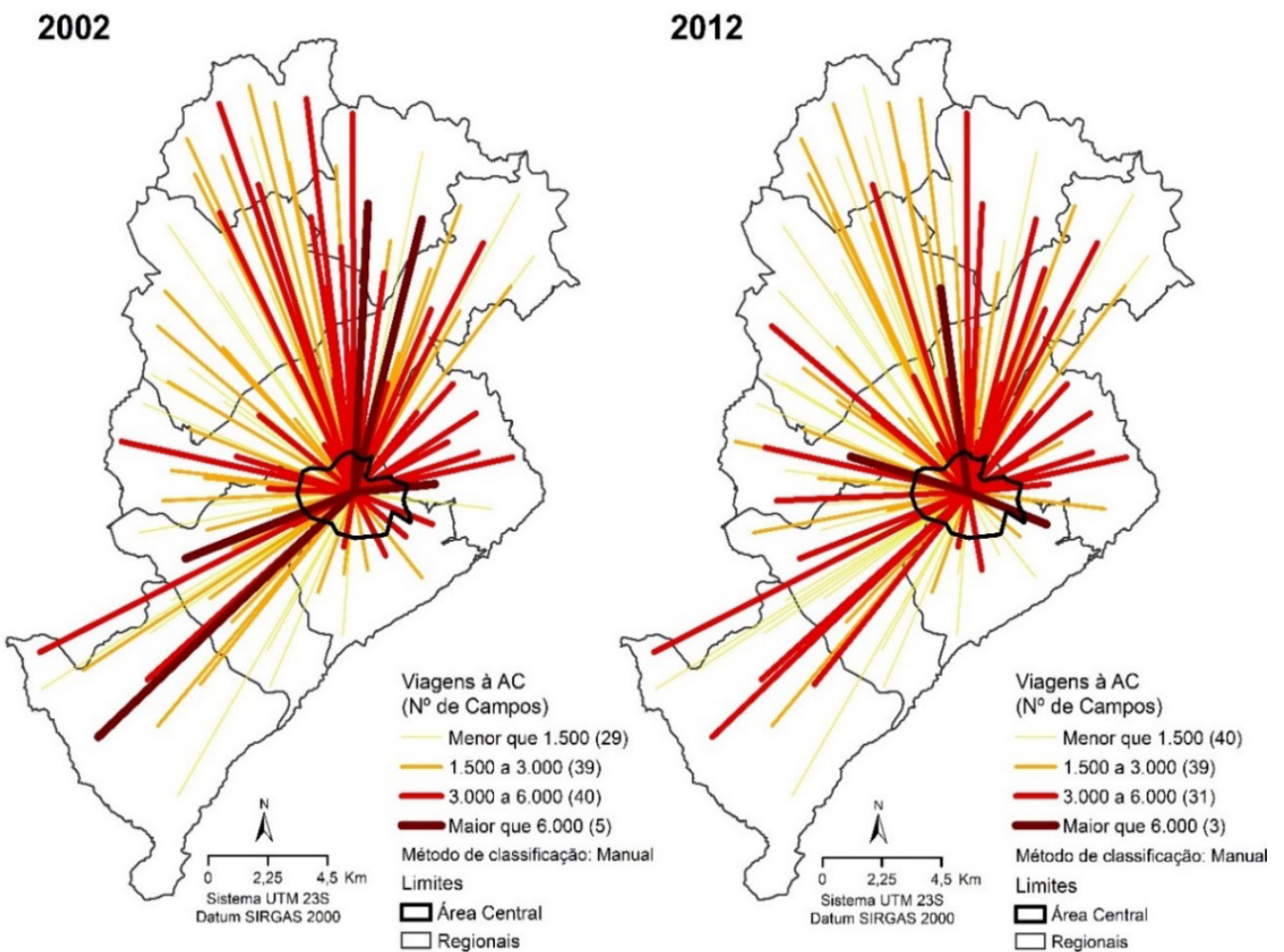

Figura 6 - Linhas de fluxos por ônibus para a AC de Belo Horizonte/MG (2002 e 2012). Fonte dos dados: Elaboração própria. Base digital das Pesquisas OD (2002 e 2012).

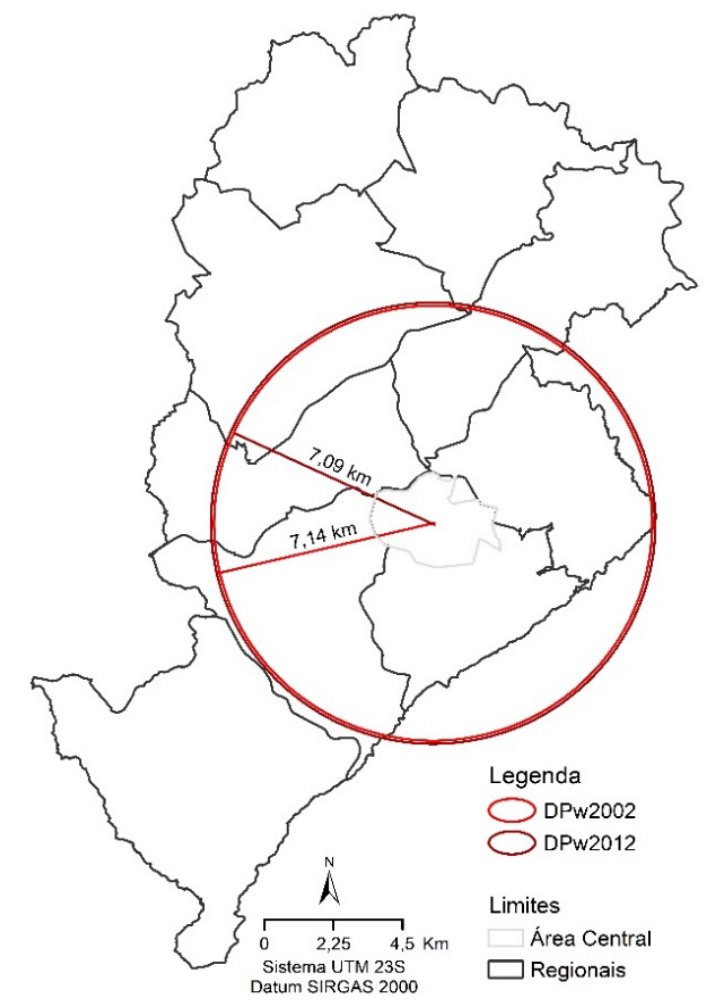

Figura 7 - Centros médios e distância padrão ponderados pelos fluxos à AC de Belo Horizonte/MG (2002 e 2012). Fonte dos dados: Elaboração própria. Base digital das Pesquisas OD (2002 e 2012). 


\section{Conclusões e considerações finais}

A análise dos dados extraídos da pesquisa "Origem e Destino" de 2002 e 2012 não confirma a perda do poder de atração da AC de Belo Horizonte. Diferentemente do suposto processo de descentralização e rompimento do modelo centro-periferia, os resultados desse trabalho indicam a prevalência de fluxos ainda fortemente concentrados, embora se estendam ao longo das principais arteriais ligadas a determinadas centralidades fora da AC. 0 modelo centro-periferia, destacado por Mendonça (2008), não se caracteriza como plenamente explicativo e requer ajustes de análise e interpretação, dada a atuação de forças ante os "novos processos de urbanização" (Soja, 2000) e a extensão da infraestrutura no município, que reduz a diferenciação espacial (Tonucci, 2009).

A consolidação de antigas e a emersão de novas centralidades, como aquelas localizadas nas regionais Barreiro, Venda Nova e Norte, indicadas no próprio Plano Diretor de Desenvolvimento Integrado da Região Metropolitana de Belo Horizonte (2011), parece sugerir a ação de forças de convergência no espaço urbano. Essas centralidades cumprem funções distintas dentro do município, indicando um processo ainda incipiente de descentralização econômica e funcional. Por exemplo, a regional Barreiro faz parte do eixo industrial da RMBH, nomeado por Villaça (2017) de "subúrbios industriais ferroviários". A implantação da Mannesmann nessa regional contribuiu para consolidar a região como forte polo industrial. É um espaço de relativa heterogeneidade, de forte traço popular e operários. Ademais, nela estão localizadas importantes atividades de comércio e serviços (Tonucci, 2009). Já as regionais Venda Nova e Norte, que fazem parte do Vetor Norte de expansão metropolitana, apresentam uma multiplicidade de pequenas centralidades de comércio e serviços e são caracterizados pela ocupação pela população de baixa renda em assentamentos populares (Diniz \& Véras, 2017).

A compreensão das diversas formas de mobilidade, mesmo que complexas e altamente dinâmicas, pode ser um instrumento relevante disponível ao processo de planejamento urbano, incluindo a formulação e proposição de políticas públicas de transporte público, consideradas à luz da estrutura de produção e consumo do espaço urbano. Como os sistemas de transporte público prevalecentes nas principais metrópoles do país, incluindo a capital mineira, são altamente convergentes às áreas centrais, as análises dos fluxos e a produção de indicadores de concentração podem oferecer informações técnicas adicionais à tomada de decisão, ainda que as decisões sejam e devam ser conduzidas na esfera política. Talvez medidas mais robustas e incisivas sejam necessárias para romper o elevado nível de concentração das atividades econômicas e de viagens pelo sistema de transporte público em Belo Horizonte.

\section{Agradecimentos}

O presente trabalho foi realizado com apoio da Coordenação de Aperfeiçoamento de Pessoal de Nível Superior - Brasil (CAPES).

\section{Referências}

Anderson, N. B., \& Bogart, W. T. (2001). The structure of sprawl: identifying and characterizing employment centers in polycentric metropolitan areas. American Journal of Economics and Sociology, 60(1), 147-169.

http://dx.doi.org/10.1111/1536-7150.00058.

Balbim, R. (2016). Mobilidade: uma abordagem sistêmica. In R. Balbim, C. Krause, \& C. Linke (Org.), Cidade e movimento: mobilidades e interações no desenvolvimento urbano (pp. 23-42). Brasília: IPEA.

Barbosa, J. L. (2014). A mobilidade urbana como expressão do Direito à Metrópole. In E. Limonad \& E. Castro (Org.), Um novo planejamento para um novo Brasil? (pp. 43-56). Rio de Janeiro: Letra Capital.

Batty, M. (2005). Cities and complexity. Cambridge: The MIT Press. 
Belo Horizonte. (2006). Centro Vivo: Programa de Requalificação da Área Central de Belo Horizonte. In Anais do I Encontro de Planejamento Estratégico para Centros Urbanos. Porto Alegre: Procempa.

Belo Horizonte. (2011). Plano Diretor de Desenvolvimento Integrado da Região Metropolitana de Belo Horizonte PDDI-RMBH (Vol. 1, Relatório Técnico, Produto 6). Belo Horizonte: UFMG.

Belo Horizonte. Prefeitura Municipal. (1996, 27 de agosto). Lei 7.165, de 27 de agosto de 1996. Plano Diretor de Belo Horizonte. Belo Horizonte: Diário Oficial do Município.

Belo Horizonte. Prefeitura Municipal. (2019, 8 de agosto). Lei 11.181, de 8 de agosto de 2019. Plano Diretor de Belo Horizonte. Belo Horizonte: Diário Oficial do Município.

Berman, M. (2007). Tudo o que é sólido desmancha no ar: a aventura da modernidade. São Paulo: Companhia de Bolso.

Bertaud, A. (2004). The spatial organization of cities: deliberate outcome or unforeseen consequence? (IURD Working Paper Series, pp. 1-32). Washington: World Bank.

Botechia, F. R. (2001). Áreas centrais em transformação os tempos e os espaços no centro tradicional de Vitória (Dissertação de mestrado). Escola de Arquitetura, Universidade Federal de Minas Gerais, Belo Horizonte.

Button, K., \& Nijkamp, P. (1997). Social change and sustainable transport. Journal of Transport Geography, 5(3), 215-218. http://dx.doi.org/10.1016/S0966-6923(97)00018-5.

Calvet, J. V. (1970). Transportes urbanos. Madrid: Editorial Dossat.

Campos, V. B. G. (2013). Planejamento de transportes: conceitos e modelos. Rio de Janeiro: Interciência.

Cardoso, L. (2007). Transporte público, acessibilidade urbana e desigualdades socioespaciais na Região Metropolitana de Belo Horizonte (Tese de doutorado). Instituto de Geociências, Universidade Federal de Minas Gerais, Belo Horizonte.

Castells, M. (2003). A sociedade em rede. São Paulo: Paz e Terra.

Corrêa, R. L. (1995). O espaço urbano. São Paulo: Editora Ática.

Costa, P. B., Morais, G. C., No., \& Bertolde, A. I. (2017). Urban mobility indexes: a brief review of the literature. Transportation Research Procedia, 25C, 3649-3659. http://dx.doi.org/10.1016/j.trpro.2017.05.330.

Chen, W., Gao, Q., \& Xiong, H.-G. (2017). Uncovering urban mobility patterns and impact of spatial distribution of places on movements. International Journal of Modern Physics C, 28(1), 1-3. http://dx.doi.org/10.1142/S0129183117500048.

Diniz, L. S., \& Véras, M. P. B. (2017). Belo Horizonte/MG: práticas de desenvolvimento do Vetor Norte Metropolitano. Geo UERJ, (30), 169-195. http://dx.doi.org/10.12957/geouerj.2017.28465.

Giuliano, G., \& Small, K. A. (1991). Subcenters in the Los Angeles region. Regional Science and Urban Economics, 21(2), 163-182. http://dx.doi.org/10.1016/0166-0462(91)90032-I.

Gottdiener, M. (1993) A produção social do espaço urbano (Tradução de G. G. de Souza). São Paulo: Editora da Universidade de São Paulo.

Grillet-Aubert, A., Guth, S., \& Clément, P. (2001). Transports et architecture du territoire: état des lieux et perspectives de recherche (Relatório de pesquisa). Paris: Institut Parisien de Recherche: Architecture Urbanistique Sociétés (IPRAUS).

Guimarães, H. A. L., Cardoso, L., Matos, R. E. S., \& Magalhães, D. J. A. V. (2005). Fatores recentes que atuam na dispersão espacial do trabalho em Belo Horizonte e Região Metropolitana. In Anais do I Congresso Luso-Brasileiro para o Planejamento Urbano, Regional, Integrado e Sustentável. São Carlos: PLURIS.

Gutiérrez, J., Condeço-Melhorado, A., \& Martin, J. C. (2010). Using accessibility indicators and GIS to assess spatial spillovers of transport infrastructure investment. Journal of Transport Geography, 18(1), 141-152.

http://dx.doi.org/10.1016/j.jtrangeo.2008.12.003. 
Haesbaert, R. (2004). Dos múltiplos territórios à multiterritorialidade. In Anais do I Seminário Nacional sobre Múltiplas Territorialidades. Porto Alegre: UFRGS.

Handy, S. (1994). Highway blues - nothing a little accessibility can't cure. Access Magazine, 1(5), 3-7. Recuperado em 30 de maio de 2017, de https://escholarship.org/uc/item/66k8b8bz

Kloosterman, R., \& Musterd, S. (2001). The polycentric urban region: towards a research agenda. Urban Studies (Edinburgh, Scotland), 38(4), 623-633. http://dx.doi.org/10.1080/00420980120035259.

Kneib, E. C., \& Silva, P. C. M. (2014). Identificação de subcentros urbanos para planejamento de transportes e mobilidade: contribuição metodológica baseada em especialistas. In E. C. Kneib (Org.), Projeto e cidade: centralidades e mobilidade urbana (pp. 45-68.). Goiânia: FUNAPE.

Lefebvre, H. (1972). Le droit à la ville suivi d'éspace et politique. Paris: Anthropos.

Lefebvre, H. (2008). A revolução urbana. Belo Horizonte: UFMG.

Lessa, D. A., Góes, P. H., Oliveira, L. K., Oliveira, R. L. M., Lobo, C., Barros, T., Moura, R., Mercier, J., Queiroz, E., \& Souza, I. A. (2018). Relações espaciais e a atratividade territorial dos lugares centrais em Belo Horizonte, Brasil. In Anais do VIII Congresso Luso-Brasileiro para o Planeamento Urbano, Regional, Integrado e Sustentável. Coimbra: PLURIS.

Lessa, D. A., Lobo, C., \& Cardoso, L. (2019). Accessibility and urban mobility by bus in Belo Horizonte/Minas Gerais - Brazil. Journal of Transport Geography, 77, 1-10. http://dx.doi.org/10.1016/j.jtrangeo.2019.04.004.

Litman, T. (2017). Evaluating transportation land use impacts: considering the impacts, benefits and costs of different land use development patterns (Relatório de pesquisa). Victoria: Victoria Transport Policy Institute (VTPI). Recuperado em 30 de maio de 2017, de http://www.vtpi.org/landuse.pdf

Lobo, C., \& Cardoso, L. (2018). Eficiência do transporte público por ônibus em Belo Horizonte/Mg: análise com base na Pesquisa Origem e Destino de 2012. Caderno de Geografia, 28(52), 25-41. http://dx.doi.org/10.5752/p.2318-2962.2018v28n52p25.

Magagnin, R. C., \& Silva, A. N. (2008). A percepção do especialista sobre o tema mobilidade urbana. Transportes, 16(1), 25-35. http://dx.doi.org/10.14295/transportes.v16i1.13.

McDonald, J. F. (1987). The Identification of Urban Employment Subcenters. Journal of Urban Economics, 21(2), 242-258. http://dx.doi.org/10.1016/0094-1190(87)90017-9.

McMillen, D. P. (2001). Polycentric urban structure: the case of Milwaukee. Economic Perspectives, 25(2), 15-25.

Mendonça, J. G. (2008). Estrutura socioespacial da RMBH nos anos 2000: há algo de novo? In J. G. Mendonça, L. T. Andrade \& C. A. Faria (Orgs.), Metrópole: território, sociedade e política. O caso da Região Metropolitana de Belo Horizonte (pp. 45-104). Belo Horizonte: PUC-Minas: Observatório das Metrópoles.

Mitra, S. K., \& Saphores, J. D. M. (2016). The value of transportation accessibility in a least developed country city The case of Rajshahi City, Bangladesh. Transportation Research Part A, Policy and Practice, 89, 184-200. http://dx.doi.org/10.1016/j.tra.2016.05.002.

Morris, J. M., Dumble, P. L., \& Wigan, M. R. (1979). Accessibility indicators for Transport planning. Transportation Research Part A, Policy and Practice, 13(2), 91-109. http://dx.doi.org/10.1016/0191-2607(79)90012-8.

Raia, A. A., Jr. (2000) Acessibilidade e mobilidade na estimativa de um índice de potencial de viagens utilizando redes neurais artificiais e sistema de informações geográfica (Tese de doutorado). Escola de Engenharia de São Carlos, Universidade de São Paulo, São Carlos.

Rochefort, M. (1998). Redes e sistemas: ensinando sobre o urbano e a região. São Paulo: Hucitec.

Rodrigue, J. P., Comtois, C., \& Slack, B. (2006). The geography of transport systems. London: Routledge.

Schoenau, M., \& Müller, M. (2017). What affects our urban travel behavior? A GPS-based evaluation of internal and external determinants of sustainable mobility in Stuttgart (Germany). Transportation Research Part F: Traffic Psychology and Behaviour, 48, 61-73. http://dx.doi.org/10.1016/j.trf.2017.05.004. 
Shaw, J., Knowles, R., \& Docherty, I. (2008). Introducing transport geographies. In R. Knowles, J. Shaw, \& I. Docherty (Eds.), Transport geographies: mobilities, flows and spaces (pp. 3-9.). Hoboken: Wiley-Blackwell.

Soja, E. W. (2000). Postmetropolis: critical studies of cities and regions. Malden: Blackwell Publishers.

Thill, J.-C. (2000). Geographic information systems for transportation in perspective. Transportation Research Part C, Emerging Technologies, 8(1-6), 3-12. http://dx.doi.org/10.1016/S0968-090X(00)00029-2.

Tonucci, J. B. M., Jr. (2009). Cidade fractal - transformações recentes na Região Metropolitana de Belo Horizonte. In Anais do XIII Encontro da Associação Nacional de Pós-Graduação e Pesquisa em Planejamento Urbano e Regional. Florianópolis: ENANPUR.

Vargas, J. C. B. (2006). 0 fenômeno da centralidade - Teoria e Prática (em Porto Alegre). In Anais do X Encontro de História e Teoria da Arquitetura do Rio Grande do Sul. Caxias do Sul: UCS.

Vasconcellos, E. A. (1996). Transporte urbano, espaço e equidade. São Paulo: FAPESP.

Villaça, F. (2017). Espaço intra-urbano no Brasil (2a ed.) São Paulo: Studio Noel, FAPESP, Lincoln Institute.

Wiel, M. (2005). Qu'est ce que la mobilité? In M. Wiel (Ed.), Questions de moilité: la moilité em question. Brest: Institut de Géoarcitecture de Brest.

Wilson, A. (2014). Complex spatial systems. The modelling foundations of urban and regional analysis. New York: Routledge. http://dx.doi.org/10.4324/9781315838045.

Zhong, C., Arisona, S. M., Huang, X., Batty, M., \& Schmitt, G. (2014). Detecting the dynamics of urban structure through spatial network analysis. International Journal of Geographical Information Science, 28(11), 2178-2199. http://dx.doi.org/10.1080/13658816.2014.914521.

Editor: Fábio Duarte

Recebido: Ago. 21, 2019

Aprovado: Fev. 23, 2020 